\title{
Patient Factors Associated with Adherence, and the Change in Cardiac Risk Factors Among Cardiac Rehabilitation Patients in Qatar
}

Rahma Ahmed Saad1, MSc, Mohamed Alhashemi², PhD, Theodoros papasavvas², PhD, Karam Adawi', PhD. ${ }^{1}$ Departnment of Public Health, College of Health science , ${ }^{2}$ Departnment of Cardiac rehabilitation, Heart Hospital

\section{Background}

cardiovascular disease is the number one killer in Qatar(1). Cardiac rehabilitation (CR) is a secondary prevention model of care for cardiac patients. It is proven that CR reduces cardiovascular mortality by $20 \%$ (2). However, CR is underutilized worldwide, with low enrolment and adherence rates (3). This study aims (a) to investigate factors associated with adherence (median number of sessions, i.e. 21), and (b) to examine the relationship between adherence and change in cardiac risk factors, i.e. blood pressure, cholesterol, and low-density lipoprotein (LDL)

\section{Method and materials}

This study consisted of 714 cardiac patients, aged $\geq 18$ years, who were referred to the cardiac rehabilitation program in Qatar. Retrospective cohort study using data from (January 2013September 2018) were analysed. Logistic regression models were used to assess factors associated with adherence. Multiple linear regression models were used to examine the relationship between the number of CR sessions attended and changes in cardiac risk factors.

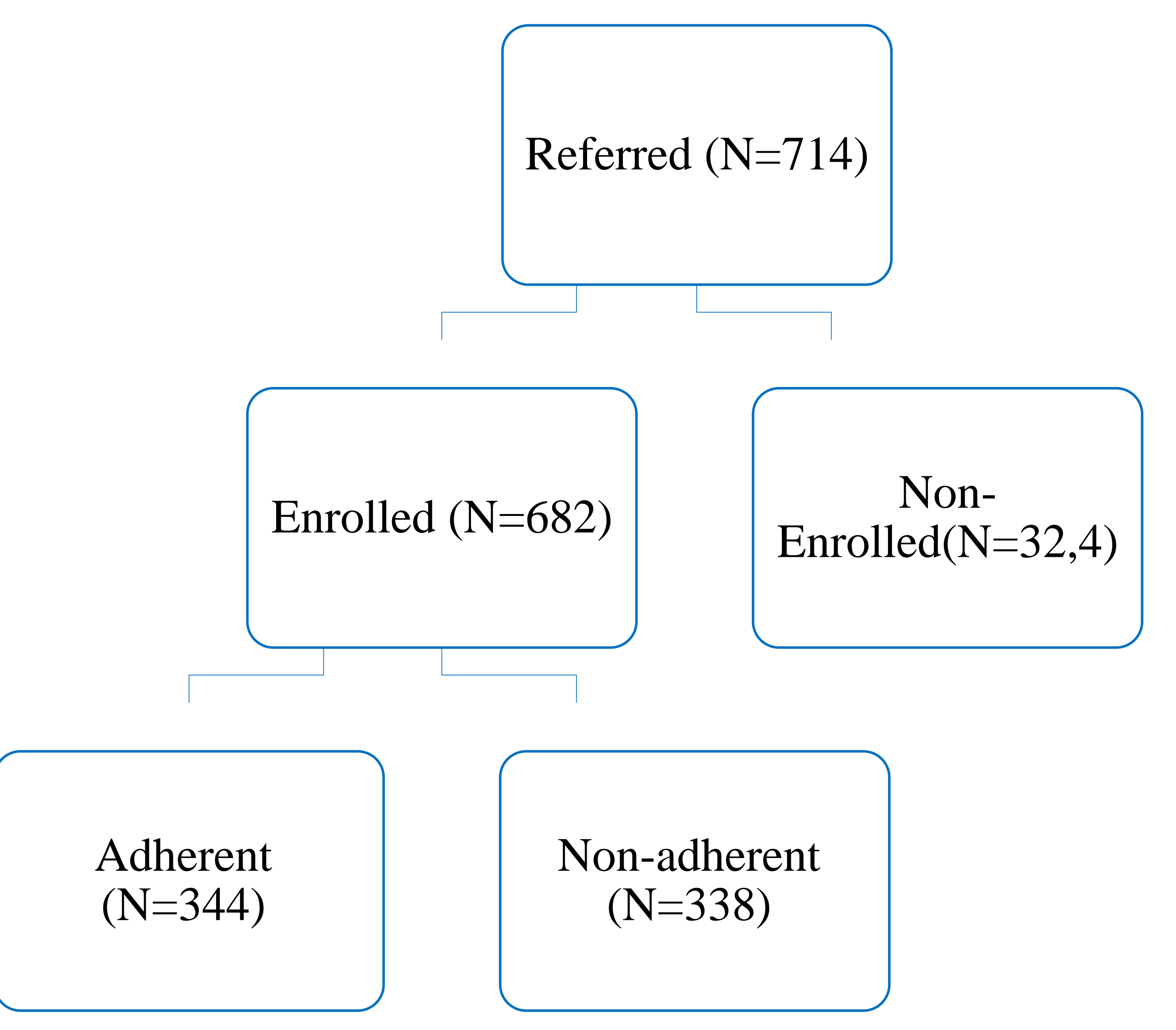

Figure1: Study Flow Chart

\section{Results}

The mean age of our population was $52.7 \pm 10.1$ years. The majority of our patients were males $(\mathrm{n}=641,89.8 \%)$ and non-Qatari $(\mathrm{n}=596,83.5 \%)$. One fourth were smokers $(\mathrm{n}=185,25.91 \%)$, and one fifth $(\mathrm{n}=128,18.8 \%)$ were diagnosed with severe depression. Patients with AACVPR moderate and high-risk levels were more likely to adhere compared to those with low risk. PCI and musculoskeletal disease were negatively associated with adherence (Table 1). We found clinically significant health improvements among adherents compared to non-adherents; reduction of $10 \%$ in cholesterol, and $15 \%$ in lowdensity lipoprotein (LDL) (Tables 2 and 3). The median number of sessions attended by the patients was 22 (Figure 2)

Table 1: Patients factors associated with adherence

\begin{tabular}{lcccc}
\hline Variables & OR & \multicolumn{2}{c}{$\mathbf{9 5 \%}$ CI } & P-value \\
\hline Age (years) & 1.01 & 0.98 & 1.04 & 0.42 \\
Gender & & & & \\
$\quad$ Female & Ref & & & \\
$\quad$ Male & 1.20 & 0.53 & 2.74 & 0.66 \\
AACVPR Risk Category & & & & \\
$\quad$ Low risk & Ref & & & \\
Moderate risk & 12.71 & 7.81 & 20.68 & $<\mathbf{0 . 0 0 1}$ \\
$\quad$ High risk & 10.60 & 6.44 & 17.44 & $<\mathbf{0 . 0 0 1}$ \\
PCI & & & & \\
No & Ref & & & \\
Yes & 0.39 & 0.17 & 0.89 & $\mathbf{0 . 0 3}$ \\
CABG & & & & \\
No & Ref & & & \\
Yes & 0.49 & 0.19 & 1.28 & 0.14 \\
Musculoskeletal diseases & & & & \\
No & Ref & & & $\mathbf{0 . 0 0 3}$ \\
Yes & 0.15 & 0.06 & 0.5 & \\
\hline
\end{tabular}

Table 2: Change in Clinical Measures Among Adherent and Non-adherent group

\begin{tabular}{lllll}
\multicolumn{1}{c}{ Measures } & \multicolumn{4}{c}{ Adherence } \\
& Pre & Post & Change & \% change \\
& & & & \\
$\mathrm{BMI}\left(\mathrm{Kg} / \mathrm{m}^{2}\right)$ & $29.18 \pm 5.36$ & $27.63 \pm 5.23$ & $-0.54 \pm 2.40$ & $-1.8 \%$ \\
$\mathrm{LDL}(\mathrm{mmol} / \mathrm{L})$ & $1.95 \pm 0.93$ & $1.26 \pm 0.78$ & $-0.31 \pm 0.86$ & $\mathbf{- 1 5 \%}$ \\
Cholesterol(mmol/L) & $3.66 \pm 1.09$ & $3.26 \pm 0.74$ & $-0.40 \pm 0.89$ & $\mathbf{- 1 0 \%}$
\end{tabular}

$\begin{array}{lllll}\mathrm{SBP}(\mathrm{mm} \mathrm{Hg}) & 130.35 \pm 18.65 & 124.98 \pm 15.81 & -5.36 \pm 17.33 & -4 \%\end{array}$

\begin{tabular}{lllll} 
Measures & \multicolumn{4}{c}{ Nonadherence } \\
BMI $\left(\mathrm{Kg} / \mathrm{m}^{2}\right)$ & $28.07 \pm 5.03$ & $27.62 \pm 5.23$ & $-0.44 \pm 2.09$ & $-1.5 \%$ \\
& & & & $-16 \%$ \\
LDL $(\mathrm{mmol} / \mathrm{L})$ & $1.95 \pm 1.02$ & $1.63 \pm 1.51$ & $-0.32 \pm 0.93$ & $-16 \%$ \\
Cholesterol $(\mathrm{mmol} / \mathrm{L})$ & $3.62 \pm 1.25$ & $3.28 \pm 0.92$ & $-0.33 \pm 0.96$ & $-9.11 \%$ \\
SBP $(\mathrm{mm} \mathrm{Hg})$ & $6.58 \pm 1.56$ & $6.32 \pm 1.30$ & $-0.25 \pm 0.94$ & $-3.79 \%$
\end{tabular}

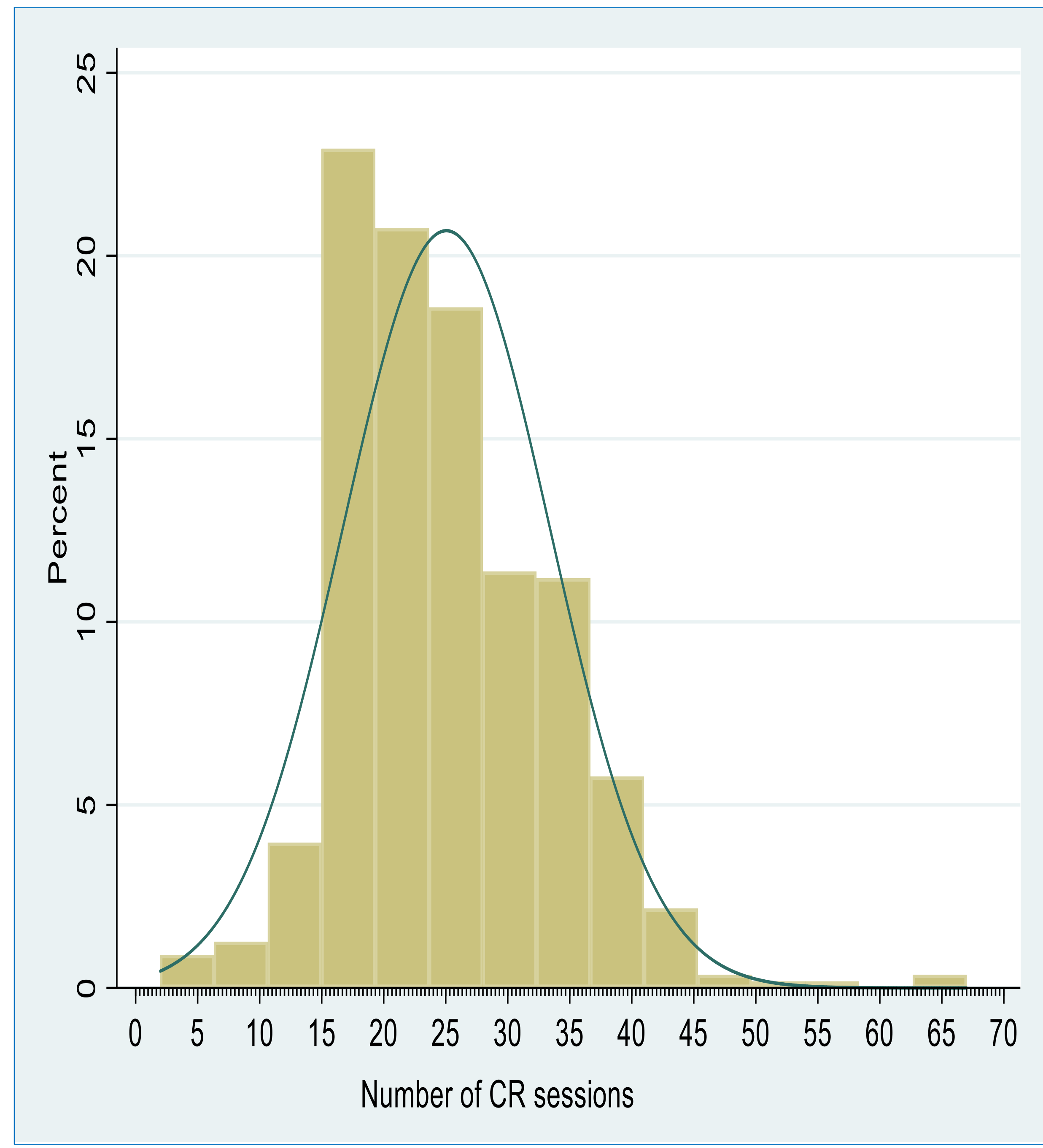

Figure2: Distribution of CR sessions attended by patients

\section{Recommendations}

Research is needed to better understand the patient factors associated with enrolment with a larger sample size. We recommend to re-conduct this study but with including those critical variables associated with enrolment and adherence, such as education, employment status, social support, and social status. A combination of quantitative and qualitative research on why people drop out of the program or what could be the reasons Qatari patients do not adhere to such programs could be a good future study in this area.

\section{Conclusion}

This study provides new insights in Qatar setting into factors that lead patients to adhere to their CR sessions. These factors represent opportunities for targeted interventions to improve CR utilization.

\begin{tabular}{|c|c|}
\hline & References \\
\hline 1. & $\begin{array}{l}\text { Ministry of Public Health. Qatar public health strategy 2017- } \\
2022 . \\
\text { Turk-Adawi, K., Sarrafzadegan, N., \& Grace, S. L. (2014). } \\
\text { Global Availability of Cardiac Rehabilitation. Nature reviews. } \\
\text { Cardiology, 11(10), 586-596. doi:10.1038/nrcardio.2014.98 } \\
\text { Anderson, L., Oldridge, N., Thompson, D. R., Zwisler, A. D., } \\
\text { Rees, K., Martin, N., \& Taylor, R. S. (2016). Exercise-Based } \\
\text { Cardiac Rehabilitation for Coronary Heart Disease: Cochrane } \\
\text { Systematic Review and Meta-Analysis. J Am Coll Cardiol, } \\
\text { 67(1), 1-12. doi:10.1016/j.jacc.2015.10.044 }\end{array}$ \\
\hline
\end{tabular}

\section{Acknowledgments}

I would like to acknowledge the department of Cardiac rehabilitation at Heart hospital for their outstanding support to my Master thesis. I would also like to thank the IRB committee at $\mathbf{Q U}$ and HMC for approving this study (Approval No. MRC 01-18-430). 